\title{
Correction to: Decision Tree Based Classification of Abdominal Aortic Aneurysms Using Geometry Quantification Measures
}

\author{
Shalin A. Parikh, ${ }^{1}$ Raymond Gomez, ${ }^{2}$ Mirunalini Thirugnanasambandam, ${ }^{1}$ \\ Sathyajeeth S. Chauhan, ${ }^{1}$ Victor De Oliveira, ${ }^{3}$ Satish C. Muluk, ${ }^{4}$ \\ MARK K. Eskandari, ${ }^{5}$ and Ender A. FinOL (ii) ${ }^{1,2}$
}

${ }^{1}$ UTSA/UTHSA Joint Graduate Program in Biomedical Engineering, University of Texas at San Antonio, One UTSA Circle, San Antonio, TX 78249, USA; ${ }^{2}$ Department of Mechanical Engineering, University of Texas at San Antonio, One UTSA Circle, San Antonio, TX 78249, USA; ${ }^{3}$ Department of Management Science and Statistics, University of Texas at San Antonio, One UTSA Circle, San Antonio, TX 78249, USA; ${ }^{4}$ Department of Thoracic \& Cardiovascular Surgery, Allegheny Health Network, Allegheny General Hospital, 320 E. North Ave., Pittsburgh, PA 15212, USA; and ${ }^{5}$ Division of Vascular Surgery and Department of Radiology, Northwestern University Feinberg School of Medicine, 420 E. Superior St., Chicago, IL 60611, USA

(published online 18 September 2018)

Correction to: Annals of Biomedical Engineering (2018)

https://doi.org/10.1007/s10439-018-02116-w

This erratum is to correct the variable name on the left hand side of Eq. (2). The correct variable name is "Diameter" rather than the stated "Area."

Address correspondence to Ender A. Finol, UTSA/UTHSA Joint Graduate Program in Biomedical Engineering, University of Texas at San Antonio, One UTSA Circle, San Antonio, TX 78249, USA. Electronic mail: ender.finol@utsa.edu

The original article can be found online at https://doi.org/10. 1007/s10439-018-02116-w. 